little is known about long term effects or its effects on fetuses and newborn infants (including those effects transmitted through breast milk).

Ensuring compliance with treatment-which is better when drugs are given by long acting intramuscular injections -may be more important than relatively small differences in therapeutic or unwanted effects, and a possible disadvantage of risperidone is the lack of a depot preparation. In the case of new drugs whose profile of unwanted effects has not been fully defined, however, administration by depot injection could lead to serious consequences.

Finally, there is the issue of cost. Twenty eight days' treatment with risperidone $6 \mathrm{mg}$ a day costs $£ 109$ compared with $£ 10$ for the same period of treatment with haloperidol $10 \mathrm{mg}$ a day. At first sight risperidone may not seem a good buy, but a cost-benefit analysis should take into account not only relative drug costs but also differential response rates; untoward effects; patients' satisfaction with treatment and their quality of life; the variable needs for inpatient care, follow up, monitoring of treatment, and involvement of other providers of care; patients' productivity, loss of earnings, and other expenses; and the effect of the illness on families and the community.

A comparative analysis of all of these has not been carried out, although a Canadian study showed that the average number of days (85) spent in hospital during the year that patients received risperidone was less than that (106) during the preceding year, when patients received older antipsychotic drugs. ${ }^{14}$ Although of interest, the results of a retrospective comparison involving only a small number of patients in one country with possibly different criteria for admission than elsewhere may not be generalisable to other countries. One explanation for the apparent benefit from risperidone could have been the extra attention that the patients received while in the research study.
The results of research published to date show hope but until more research (including full cost-benefit analyses) has been carried out doctors and purchasers of health care will have to decide on the basis of their experience and ethics whether the benefits justify the cost.

J GUY EDWARDS

Honorary clinical senior lecturer

University Department of Psychiatry,

Royal South Hants Hospital,

Southampton SO9 4PE

1 Duinkerke SJ, Botter PA Jansen AAI, Van Dongen PAM, Van Haaften AJ, Boom AJ, et al Ritanserin, a selective 5-HT2/C antagonist, and negative symptoms in schizophrenia. A Ritanserin, a selective 5-HT2/IC antagonist, and negative symp
placebo-controlled double-blind trial. Br $\mathcal{Y}$ Psychiatry 1993;163:451-5.

2 Janssen PAJ, Niemegeers CJE, Awouters F, Schellekens KHL, Megens AAHP, Meert TF Pharmacology of risperidone ( $R$ 64 766), a new antipsychotic with serotonin-S2 and dopamineD2 antagonistic properties. ₹ Pharmacol Exp Ther 1988;244:685-93.

3 Leysen JE, Gommeren W, Eens A, de Charroy de Courcelles D, Stoof JC, Janssen PA Biochemical profile of risperidone, a new antipsychotic. 9 Pharmacol Exp Ther 1988;247:661-70.

4 Leysen JE, Janssen PMF, Gommeren W, Wynants J, Pauwels PJ, Janssen PAJ. In vitro and in vivo receptor binding and effects on monoamine turnover in rat brain regions of the novel antipsychotics risperidone and ocaperidone. Molecular Pharmacology 1992;41:494-508.

5 Megens AAHP, Awouters FHL, Schotte A, Meert TF, Dugovic C, Niemegeers CJE, et al. Survey on the pharmacodynamics of the new antipsychotic risperidone. Psychopharmacology 1994;114: 9-23.

6 Borison RL, Pathiraja AP, Diamond BI, Meibach RC. Risperidone: clinical safety and efficacy in schizophrenia. Psychopharmacol Bull 1992;28:213-8.

7 Claus A, Bollen J, De Cuyper H, Eneman M, Malfroid M, Peuskens J, et al. Risperidone versus haloperidol in the treatment of chronic schizophrenic inpatients: a multicentre double-blind comparative study. Acta Psychiatr Scand 1992;85:295-305.

8 Chouinard G, Jones B, Remington G, Bloom D, Addington D, MacEwan GW, et al. A Canadian multicenter placebo-controlled study of fixed doses of risperidone and haloperidol in the treatment of chronic schizophrenic patients. 9 Clin Psychopharmacol 1993;13:25-40.

9 Hoyberg OJ, Fensbo C, Remvig J, Lingjaerde O, Sloth-Nielsen M, Salvesen I. Risperidone versus perphenazine in the treatment of chronic schizophrenic patients with acute exacerbations. Acto Psychiatr Scand 1993;88:395-402.

10 Heinrich K, Klieser E, Lehmann E, Kinzler E, Hruschka H. Risperidone versus clozapine in the treatment of schizophrenic patients with acute symptoms: a double blind, randomised trial. Prog Neuropsychopharmacol Biol Psychiatry 1994;18:129-37.

11 Kane JM. New antipsychotic drugs. A review of their pharmacology and therapeutic potential. Drugs 1993;46:585-93.

12 Livingston MG. Risperidone. Lancet 1994:343:457-60.

13 Edwards JG. The untoward effects of antipsychotic drugs: pathogenesis and management. In: Bradley PB, Hirsch SR, eds. The psychopharmacology and treatment of schizophrenia. Oxford: Oxford University Press, 1986:403-41.

14 Addington DE, Jones B, Bloom D, Chouinard G, Remington G, Albright P. Reduction of hospital days in chronic schizophrenic patients treated with risperidone: a retrospective study. Clinical Therapeutics 1993;15:917-26.

\title{
Preventing injuries in childhood
}

\section{A new journal for the main cause of childhood mortality and morbidity}

What is the leading cause of death among children and adolescents? Not AIDS, not cancer or diabetes, not cystic fibrosis or heart disease, and certainly not meningitis. For most countries in the developed world, and increasingly in the developing world as well, about one half of all deaths after the first year of life are due to injuries-unintentional and intentional. In Britain in 1990 injuries caused a quarter of deaths in those aged 1-4, more than a third in those aged 5-14, and three of every five deaths in those aged 15-19. Many people - professional and lay-are astonished by these figures.

Despite the frequency, and often serious medical and psychological consequences, of injuries, scientific reports about them are not often found in medical journals. Instead, reports are scattered in numerous other publications, many of them non-medical. While this is understandable given the varied disciplines that make important contributions to the control of injury-for example, engineering, road safety, psychology, and law-the failure of medical journals to register the importance of injuries is more difficult to comprehend. Thus a journal is needed that is accessible to doctors and all others interested in the subject. That is why the BMJ Publishing Group will next March be launching Injury Prevention.

Distressing as the number and seriousness of injuries may be, even more regrettable is the widespread failure to appreciate the extent to which most are preventable. Compounding this ignorance is a widespread failure to implement what is known-and much more is known about the causes of most injuries than is generally recognised.

We must acknowledge, however, that many questions remain unanswered. For example, do boys have consistently higher rates of injury than girls simply because of increased exposure to risk? And, if so, is it innate or socially conditioned? The consistent socioeconomic gradients found for most injuries (with poor people suffering many more) are also puzzling, as are national differences in mortality. Even the impressive recent decline in mortality from injuries seen in many Western nations lacks an explanation. Finally, an overriding methodological challenge is to find accurate ways of measuring exposure in a variety of potentially injurious circumstances.

Much more also needs to be learnt about how best to combine public education with regulation and legislation to change behaviours. Similarly, we need to discover how to fit local circumstances to national control strategies and how best to use input from the community. An overriding concern is to ensure that those responsible for implementing scientific knowledge are made fully aware of the results of research. To 
do so the information must be presented in an easily digestible form. Equally, investigators often fail to appreciate the many severe constraints that policymakers experience when trying to implement programmes to control injuries.

That is why this new journal is being launched. It is needed not only because the topic is so important, and because of the need to link knowledge to action, but also because no other journal currently exists that exclusively addresses this problem in young people. Injury Prevention will be the official publication of the International Society of Child and Adolescent Injury Prevention and will be distributed to all members of the society. The journal faces two principal challenges: firstly, to bridge the gap between researchers and implementers; and, secondly, it must facilitate communication among those from different disciplines and different countries who share a commitment to the control of injuries.

To meet the first test Injury Prevention will contain rigorously peer reviewed scientific material whose relevance to practitioners will be made evident. It will also include accounts of the frustrations and achievements of the burgeoning number of injury prevention groups. To help meet the second challenge the journal will be both international and interdisciplinary, which is reflected in the composition of its editorial board.
Although the main focus is on children and adolescents, papers dealing with injuries to adults from which there are lessons that apply to young people will also be welcome. Similarly, whereas the main focus is on unintentional injury, the growth in homicide and violence involving children and adolescents warrants papers on these injuries being included as well, though papers dealing exclusively with child abuse lie beyond the remit of Injury Prevention.

For Europeans more familiar with the term "accident" than "injury" the choice of the latter is deliberate. It is intended to signal the growing view that most injuries are not random events-that is, not accidental-but, rather, predictable events which therefore can be prevented. ${ }^{1}$ That is the urgent mission of this new journal.

$B M \mathcal{F}$

RICHARD SMITH

Editor

I BARRY PLESS

Editor, Injury Prevention

Montreal Children's Hospital,

2300 Tupper Street,

Montreal,

Quebec H3H 1P3,

Canada

1 Evans L. Medical accidents: no such thing? BMF 1993;307:1438-9.

\section{On advising politicians}

\section{Doctors must do better than those at last week's forum in Rhodes}

Health professionals have often claimed that politicians do not listen to them. When given the opportunity to have their voices heard they do not always make the most of it.

The Rhodes health forum, convened under the Greek presidency of the European Union last week, offered an opportunity for ministers of health and professionals to come together to discuss ways of making fundamental choices on health. Reflecting the interests of the Greek minister of health, a cardiologist, the meeting focused on what might be done to tackle cardiovascular disease.

This was an important meeting and one of the first attempts to bring together politicians and professionals since the Maastricht treaty came into force. Article 129 of the treaty has given the European Union competence in public health for the first time. This should be welcomed for at least three reasons. Firstly, many European Union policies, including policies on agriculture, transport, and the free movement of goods and services, directly affect health. Secondly, it would be hopelessly inefficient if each member state attempted to replicate research being done elsewhere on topics such as the assessment of technology, and thirdly the wide diversity of rates of disease and health policy in member states provides a valuable laboratory from which we can all learn.

Although this presents many opportunities, ministers of health and the commission have to make choices about how best to deploy limited resources. Health professionals have a crucial part to play in this process. But politicians and professionals are only two of the groups that help set priorities. There is also a need to involve the public (including patients) and to assemble evidence based on high quality research. Unfortunately, the last two were conspicuously absent from the forum.

Speaker after speaker repeated the same messages, often using the same slides and mostly ignoring the title that they had been given. The messages were that ischaemic heart disease killed more Europeans than any other condition and that high cholesterol concentrations increased the probability of having a myocardial infarction. The implied messages, put forward with varying degrees of subtlety, were that the European Union should establish a programme to tackle cardiovascular disease along the lines of the "Europe against cancer" and "Europe against AIDS" programmes and that member states should support widespread lipid screening.

Many speakers ignored basic principles, such as the need to standardise data for age and the difference between association and causation. International comparisons ignored definitional problems in everything from diagnostic labelling through medical specialists to levels of spending.

Evidence on the effectiveness of interventions was skirted over. When it was mentioned speakers showed slides with lists of studies on, for example, the effect of reducing cholesterol concentration on total mortality and dismissed those that showed no effect. Many important topics received little or no attention, including the low use of secondary prevention, the level of inappropriate use of other interventions, and ways in which the commission might seek to address diet and tobacco consumption. Recent work on, for example, the role of aspirin in secondary prevention ${ }^{1}$ and the effectiveness of screening in primary $\operatorname{care}^{23}$ went virtually unmentioned.

But how can things be improved in future? Those responsible for organising the professional input into such occasions should consider certain issues.

When professionals seek to help set priorities they must make explicit the criteria that they are using. Any interest group can make a case for investment in its subject. The presentation of data on the numbers of deaths before a certain age can be used in support of arguments for increased action 